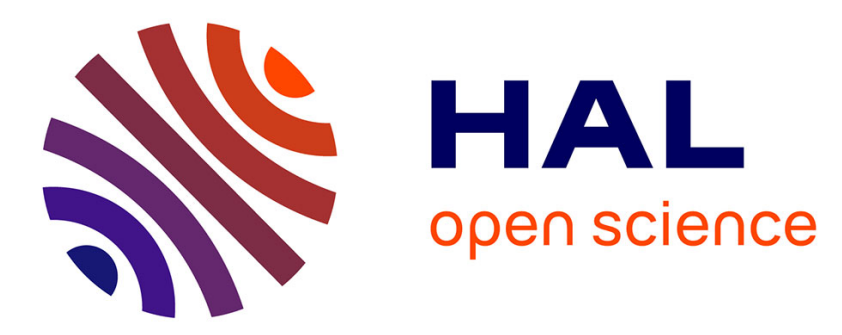

\title{
Thermal energy conversion by coupled shape memory and piezoelectric effects
}

Dimitri Zakharov, Gor Lebedev, Orphée Cugat, Jérôme Delamare, Bernard Viala, Thomas Lafont, Alexander Shelyakov

\section{- To cite this version:}

Dimitri Zakharov, Gor Lebedev, Orphée Cugat, Jérôme Delamare, Bernard Viala, et al.. Thermal energy conversion by coupled shape memory and piezoelectric effects. PowerMems 2011, Nov 2011, Séoul, South Korea. pp.106-109, 10.1088/0960-1317/22/9/094005 . hal-00646547

\section{HAL Id: hal-00646547 https://hal.science/hal-00646547}

Submitted on 17 Jan 2020

HAL is a multi-disciplinary open access archive for the deposit and dissemination of scientific research documents, whether they are published or not. The documents may come from teaching and research institutions in France or abroad, or from public or private research centers.
L'archive ouverte pluridisciplinaire HAL, est destinée au dépôt et à la diffusion de documents scientifiques de niveau recherche, publiés ou non, émanant des établissements d'enseignement et de recherche français ou étrangers, des laboratoires publics ou privés. 


\title{
THERMAL ENERGY CONVERSION BY COUPLED SHAPE MEMORY AND PIEZOELECTRIC EFFECTS
}

\author{
Dmitry Zakharov $^{1 *}$, Gor Lebedev ${ }^{1,2}$, Orphee Cugat ${ }^{1}$, Jerome Delamare ${ }^{1}$, Bernard Viala ${ }^{2}$, \\ Thomas Lafont ${ }^{1}$, Alexander Shelyakov ${ }^{3}$ \\ ${ }^{1}$ G2Elab, Grenoble Electrical Engineering Lab, CNRS-UJF-INPG, St Martin d'Hères, France \\ ${ }^{2}$ CEA, LETI, MINATEC Campus, Grenoble, France \\ ${ }^{3}$ National Research Nuclear University "MEPhI", Moscow, Russia \\ *Presenting Author: dmitry.zakharov@g2elab.grenoble-inp.fr
}

\begin{abstract}
A new concept of thermal-to-electric energy conversion by coupling shape memory effect (SME) and direct piezoelectric effect (DPE) is proposed, and two prototypes of thermal energy harvesters are fabricated and tested experimentally. First is a hybrid laminated composite consisting of TiNiCu shape memory alloy (SMA) and Macro Fiber Composite (MFC) piezoelectric. This composite had $0.1 \mathrm{~cm}^{3}$ of active materials and harvested $75 \mu \mathrm{J}$ of energy for a temperature variation of $60{ }^{\circ} \mathrm{C}$. The second prototype is a SME/DPE "machine" which uses the thermally induced linear strains of SMA and bends a bulk PZT ceramic plate through a specially designed mechanical structure. The SME/DPE "machine" with $0.2 \mathrm{~cm}^{3}$ of active material can harvest $90 \mu \mathrm{J}$ at heating and 60 $\mu \mathrm{J}$ at cooling by $20^{\circ} \mathrm{C}$. In contrast to usual pyroelectric materials, the proposed harvester is compatible with small and slow temperature variations. The integration into MEMS using sub-micron multilayers of active materials is currently under way.
\end{abstract}

Keywords: energy harvesting, piezoelectric, shape memory alloy

\section{INTRODUCTION}

The increasing demand in alternative energy sources for low-power electronics and autonomous wireless sensors has given rise to substantial research activities in the field of energy harvesting. Among the different energy sources, thermal sources are widely available. Thermal energy can be directly converted into electricity by means of thermoelectric (Seebeck effect) or pyroelectric materials. Thermoelectric power generators have already been demonstrated. However, such devices require large spatial temperature gradients in order to be efficient. Another scheme is to indirectly convert heat into electricity through mechanical transformations. This concept requires two materials being mechanically coupled. The first material (i.e. sensor) must exhibit a large thermally induced strain. The second material (i.e. convertor) must exhibit a large stress-induced electric field. In this way, the thermally induced strain is converted to voltage. This paper investigates the coupling between a shape memory alloy (SMA) and a piezoelectric material. In the vicinity of thermoelastic martensitic phase transition temperatures SMAs exhibit the largest thermally induced strains (up to $10 \%$ ) compared to any other inorganic material [1]. Together with a large stress generated at transformation, it results in the largest actuation energy density for SMAs (up to $100 \mathrm{~J} / \mathrm{cm}^{3}$ ) compared to any other known material [1]. The best candidates for SMA are NiTi and TiNiCu alloys which are widely used for industrial applications. Regarding piezoelectric materials, PZT has the highest piezoelectric constants. Thus, by coupling TiNiCu with PZT, one may expect efficient indirect thermal-to-electrical energy conversion.

\section{MATERIALS AND METHODS Hybrid laminated composite}

In this work, a SMA/piezoelectric laminated composite was fabricated for small temperature variation energy harvesting (Fig. 1). The prototype harvester was realized by assembling SMA and piezoelectric materials into a bilayer structure using cyanoacrylate glue. The piezoelectric layer was a commercial P1-type Macro Fiber Composite (MFC) from "Smart Materials Inc." [2]. It consists of $100 \mu \mathrm{m}$ diameter PZT fibers aligned horizontally between top and bottom electrodes and packed within thin polymer insulating films (Kapton). P1-type uses the superior $\mathrm{d}_{33}$ piezoelectric effect of PZT combined with interdigitated electrodes. When being elongated or shortened, the PZT fibers generate electrical charges which can be collected at the bonding pads.

The SMA layer was a $40 \mu \mathrm{m}$ thick $\mathrm{Ti}_{50} \mathrm{Ni}_{25} \mathrm{Cu}_{25}$ ribbon prepared by melt spinning technique as described in [3]. The ribbon was vacuum annealed for $5 \mathrm{~min}$ at $500{ }^{\circ} \mathrm{C}$ to obtain a suitable microcrystalline structure. For the fabricated composite the phase transition temperature region was measured to be from 50 to $80{ }^{\circ} \mathrm{C}$ which is in agreement with previous work [4]. Before assembling, the $\mathrm{TiNiCu}$ ribbon was pseudo-plastically pre-stressed in order to define a preferential deformation direction of the SMA during thermoelastic transformation as described in [4].

To induce the thermoelastic deformation of TiNiCu, the ribbon was heated by applying a direct electrical current. The resistance of the $\mathrm{TiNiCu}$ ribbon was $1,6 \Omega$ and a power of $2 \mathrm{~W}$ was used increasing its temperature from ambient to $80{ }^{\circ} \mathrm{C}$ in about 1 minute. 


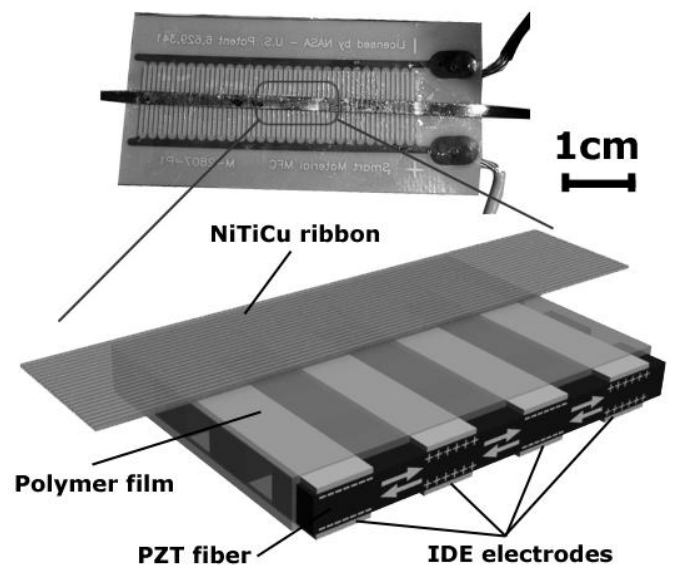

Fig. 1: Photo and schematic view of the thermal energy composite harvester demonstrator. The TiNiCu ribbon is glued onto the MFC with cyanoacrylate glue.

Different schemes of energy harvesting were previously investigated by our group [5]. In this paper we present an instant discharge mode (no cycling). For different heating times, the electrical charges were discharged instantly twice: (1) after Joule heating and (2) after natural cooling. For this purpose, the MFC electrodes are connected to the oscilloscope entrance through a $10 \mathrm{M} \Omega$ probe with an additional switch.

\section{Hybrid SME/DPE "machine"}

The second approach tested in this work was a hybrid SME/DPE "machine" using localized bonding between the two materials. SMA in the form of ribbon or wire is connected at its ends with a PZT plate through some intermediate elastic body (Fig. 2). Thereby, the SME/DPE "machine" uses the thermally induced linear strains of SMA (up to $5 \%$ ) which bends a PZT cantilever-type plate through a specially designed, flexible mechanical structure (http://www.youtube.com/watch?v=uS0z4ZEBeYw).

The role of spring in this "machine" is to provide a shape recovery of the SMA during cooling. We remind that normal SME is a one-way effect since only the high-temperature shape is memorized. It should be noted that an optimized SME/DPE "machine" will not need any spring since the piezoelectric material will be thicker and will act as a spring itself. The optimized PZT thickness will allow (1) to use all the strain generated by SMA and (2) to be stiff enough to return the SMA to its initial shape upon cooling.

The performance of the SME/DPE "machine" was studied for different configurations of PZT doubleplates: serial and parallel electrical connections, with and without intermediate elastic spacer. Several SMAs were used: NiTi wires and $\mathrm{TiNiCu}$ ribbons, with various transition temperatures. Different heating modes (continuous and pulsed) and electrical discharge schemes (with and without electrical switch) were studied.

In this paper we present only the results for the following case: (1) NiTi wire as SMA, (2) continuous heating mode (no cycling), (3) electrical switch was used for electrical discharge, (4) PZT-double plate consisting in two PZT ceramic plates with a serial electrical connection. The results for other configurations will be published elsewhere.
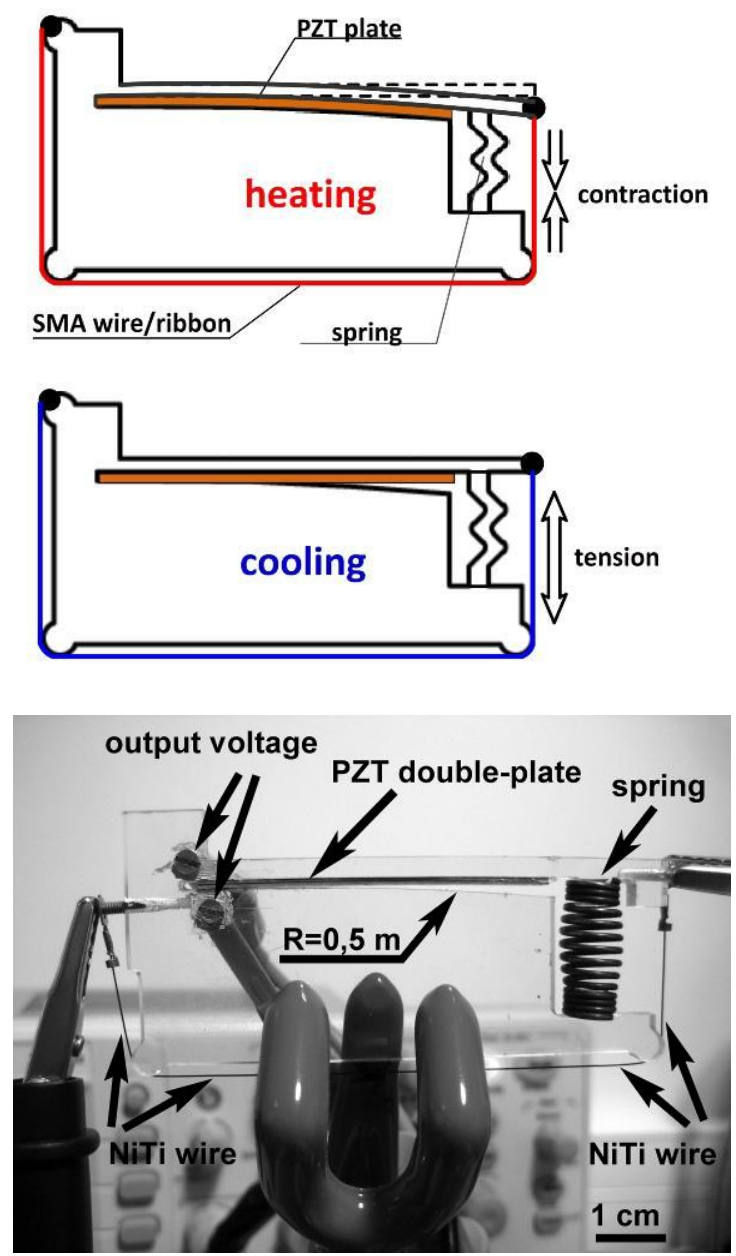

Fig. 2: Schematic views and photo of the SME/DPE harvester demonstrator. The NiTi wire is drawn around 3 sides of the plexyglass bending system (to save space). A PZT double-plate is inserted in the bending frame. Electrical contacts on the left and on the right are used for applying the heating current to the NiTi wire.

Commercial "PIC 255"-type PZT plate from "PI Ceramic GmbH" was used [6]. A $0.5 \mathrm{~mm}$ thick plate was cut into $50 \times 6 \mathrm{~mm}$ pieces. 2 pieces were glued together using non-conductive commercial epoxy adhesive "3M Scotch-Weld DP460 Off-White" locally substituted with silver lacquer to provide electrical connection between the electrodes. The sides of connection were chosen in such a way as to provide the charges of opposite signs on double-plate sides at bending. After application of epoxy on the PZT plates and their connection, the double-plate was pressed at room temperature for 24 hours. The calculation of such a double-plate capacitance using the permittivity value taken from the supplier $\left(\varepsilon_{33} / \varepsilon_{0}=1750\right)$ gives the value of $4.7 \mathrm{nF}$.

Commercial NiTi wire from "Memry Corp." was $13 \mathrm{~mm}$ long with a diameter of $250 \mu \mathrm{m}$. The wire was heated up during about $3 \mathrm{~s}$ through the thermoelastic 
transformation using $1.7 \mathrm{~W}$ of Joule heating thus provoking its shortening by $5 \mathrm{~mm}$. When the wire shortens, the PZT double-plate becomes constrained in the Perspex bending frame which is shaped as an arc with a constant curvature radius of $0.5 \mathrm{~m}$. Thereby the piezoelectric is subjected to a homogenous bending deformation. With an assumption of pure bending the maximal strain in the piezoelectric $\varepsilon_{\max }$ can be found as:

$$
\varepsilon_{\max }=\frac{h}{R}
$$

where $h$ is a single-plate thickness and $R$ is the curvature radius. In our case $\varepsilon_{\max }=0.1 \%$. This value is close to the elastic strain limit in PZT $(0.015 \%)$.

\section{RESULTS AND DISCUSSION Hybrid laminated composite}

Fig. 3 shows the results of a series of experiments using the instant discharge mode (with a switch). This mode is the most appropriate scheme to evaluate the maximum useful harvested electrical energy from the SMA/piezoelectric composite [5]. Two parameters influence the useful harvested energy value: (1) the temperature which the composite was heated to and (2) the time needed to reach that temperature.

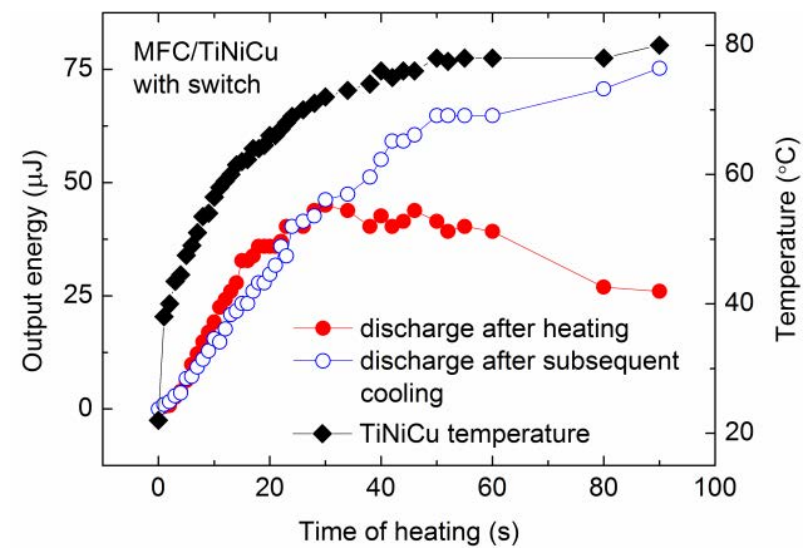

Fig. 3: Useful energy harvested by the SMA/piezoelectric composite as a function of heating time by direct Joule current heating (filled circles) and subsequent natural air cooling to room temperature (empty circles). The corresponding measured SMA temperature is also shown (filled rhombs).

For each experimental point, the switch was turned on for a short period (about $1 \mathrm{~s}$ ) twice: (1) just after heating; (2) after cooling from the reached temperature down to $23{ }^{\circ} \mathrm{C}$. The discharge time through the $10 \mathrm{M} \Omega$ probe on the oscilloscope was about $100 \mathrm{~ms}$, thus the switching on period (1 s) was enough to collect all the charges.

An increase of the useful harvested energy both for heating and cooling cases is observed when increasing heating time up to $30 \mathrm{~s}$, corresponding to $70{ }^{\circ} \mathrm{C}$. This harvested energy increase is due to the thermoelastic strain increase. When increasing the heating time up to
$100 \mathrm{~s}\left(80{ }^{\circ} \mathrm{C}\right)$, the energy harvested after cooling increases, but not that harvested after heating. This seems to be due to different charge relaxation kinetics during heating and cooling.

Additionally, significant voltage was observed even at temperatures below $40{ }^{\circ} \mathrm{C}$, which are beyond the thermoelastic transformation region. This can be explained by inhomogeneous heating. Indeed, thermal imaging revealed temperature inhomogeneities over the surface of the ribbon with hot points localized on the extremities (parts not connected to MFC [5]). This could be due to the fact that contact between the TiNiCu ribbon and the MFC substrate is not perfect. In contrast, at cooling the center of the ribbon cools down with a delay due to the large surface of contact with the MFC. Some contribution of pyroelectricity is also possible.

It is worth noting that, this scheme provides good mechanical energy transfer from the shape memory material to the piezoelectric and makes the system compact. On the other hand, its disadvantage is that the piezoelectric participates in the heat exchange. Thereby the system is more thermally inert and requires more heat energy from the environment.

Moreover, some pyroelectricity could contribute to our results, which needs to be investigated further.

Therefore, in this work another approach was also explored with a hybrid SME/DPE "machine" using localized bonding between the two materials.

\section{Hybrid SME/DPE "machine"}

Fig. 4 shows the thermoelectric response of the SME/DPE "machine". The voltage was generated by PZT double-plate which bent due to NiTi wire heating. During bending, the electrical circuit remains open. Just after the bending was complete the electrical circuit was closed with the switch. Fig. 4 shows the voltage discharged in the $10 \mathrm{M} \Omega$ oscilloscope entrance. The harvested energy was calculated as a surface under the curve of output voltage squared vs. time and was about $91 \mu \mathrm{J}$ in the case of a double-plate with intermediate spacer.

Fig. 5 shows a thermoelectric response of SME/DPE "machine" after natural air cooling of the NiTi wire. Similarly to the case of heating, the electrical switch closed the circuit just after the PZT double-plate recovered its straight shape. The harvested energy was similarly calculated to be $61 \mu \mathrm{J}$.

The capacitance of the PZT double-plate was determined from these curves using the values of peak voltage and electrical energy is about $4 \mathrm{nF}$. This is in agreement with the value calculated from material constants $(4.7 \mathrm{nF})$. This means that no damage occurred on the PZT plates during the tests.

When the electrical circuit is open one could expect that the electrical charges will not dissipate at the PZT electrodes. However, it was found that the charges vanish rather quickly: typically $15 \mathrm{~s}$ was enough for complete vanishing. This may be due to 
some parasitic electrical connections between the PZT electrodes, but no clear evidence has been found. It also means that some harvested energy was lost before closing the circuit and the achieved values were not maximal.

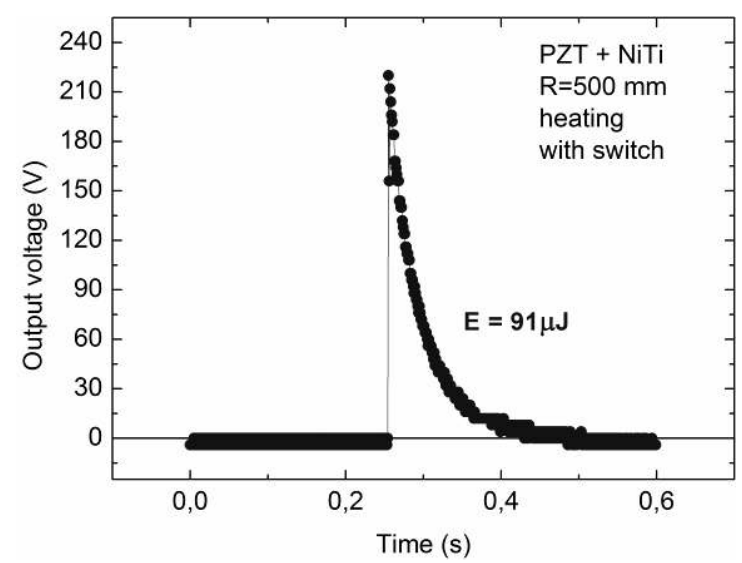

Fig. 4: Output voltage generated by the SME/DPE "machine" harvested from a single heating of NiTi wire through the thermoelastic transition temperature region. The voltage is discharged in the $10 \mathrm{M} \Omega$ oscilloscope entrance immediately after heating (with a switch).

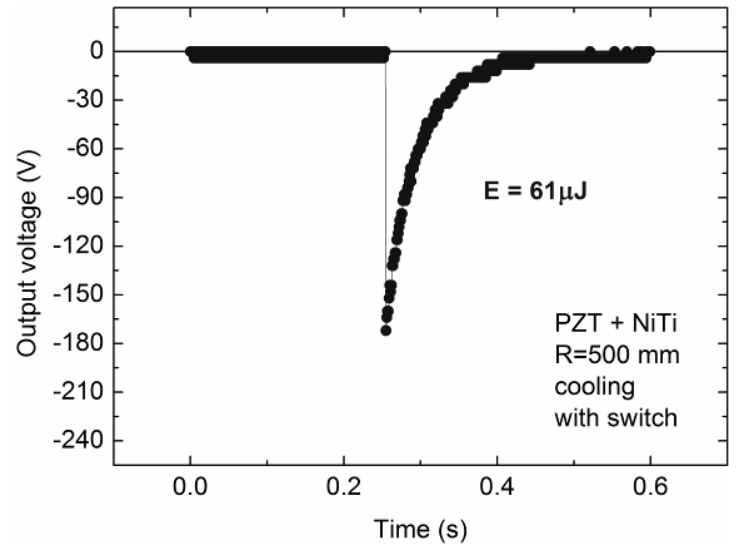

Fig. 5: Output voltage generated by the SME/DPE "machine" harvested from a single cooling of NiTi wire through the thermoelastic transition temperature region. The voltage is discharged in the $10 \mathrm{M} \Omega$ oscilloscope entrance immediately after cooling (with a switch).

\section{CONCLUSION}

We report a new concept of thermal-to-electric energy conversion by coupling SME and DPE. Two approaches were studied in this work.

First is a hybrid laminated composite consisting of TiNiCu SMA and MFC piezoelectric material. This composite had $0.1 \mathrm{~cm}^{3}$ of active materials and harvested $75 \mu \mathrm{J}$ of energy by a single temperature variation of $60^{\circ} \mathrm{C}$ (the minimum required energy for a standard wireless sensor is $30 \mu \mathrm{J})$. We also reported significant harvested thermal energy at medium frequencies which is unique to our knowledge [5].

The second prototype was a hybrid SME/DPE "machine" which uses the thermally induced linear strains of SMA to bend a PZT plate through a specially designed mechanical structure. A non-optimized SME/DPE "machine" using $0.2 \mathrm{~cm}^{3}$ of active materials can harvest $90 \mu \mathrm{J}$ at heating and $60 \mu \mathrm{J}$ at cooling.

Different from usual pyroelectric materials, the proposed harvesters are compatible with small and slow temperature variations. This opens a new opportunity to harvest thermal energy from natural sources. Since SME and DPE do not lose their efficiency at the microscale, the proposed concept is suitable for MEMS. MEMS harvester fabrication is now in progress using sub-micron multilayers.

In this work Joule heating of SMA was needed to reach the temperature of phase transition. For real harvesting of ambient temperature fluctuations, the chemical composition of the SMA should be optimized in order to reduce the phase transition temperatures to room temperature, according to [7].

The proposed method of conversion of the thermal energy to electrical energy is not direct. Thus, the intimate coupling between SMA and piezoelectric is a critical point and must be optimized. The proposed concept opens an opportunity to harvest thermal energy from natural sources.

\section{ACKNOWLEDGMENTS}

This work was supported by the French National Research Agency (ANR) under the Carnot Institute Program and by the Nanosciences Foundation of Grenoble under RTRA program.

\section{REFERENCES}

[1] Lagoudas D C 2008 Shape Memory Alloys: Modeling and Engineering Applications (New York, Springer)

[2] Smart Material MFC technical data sheet 2010 http://www. smart-material.com

[3] Shlossmacher P, Boucharat N, Rösner H et al. 2003 Crystallization studies of amorphous meltspun $\mathrm{Ti}_{50} \mathrm{Ni}_{25} \mathrm{Cu}_{25}$ J. Phys. IV France 112 731734

[4] Zakharov D, Lebedev G, Koledov V et al. 2010 An enhanced composite scheme of shape memory actuator for smart systems Physics Procedia 10 58-64

[5] Lebedev G et al 2011 Proc. 16 ${ }^{\text {th }}$ Int $t^{\text {al }}$ Conf. on Solid-State Sensors, Actuators and Microsystems, Transducers 2011 (5-9 June 2011, Beijing, China)

[6] www.piceramic.com/piezo_materials_2.php

[7] Miyazaki S, Fu Y, Huang W 2009 Thin Film Shape Memory Alloys: Fundamentals and Device Applications (New York, Cambridge University Press) 